
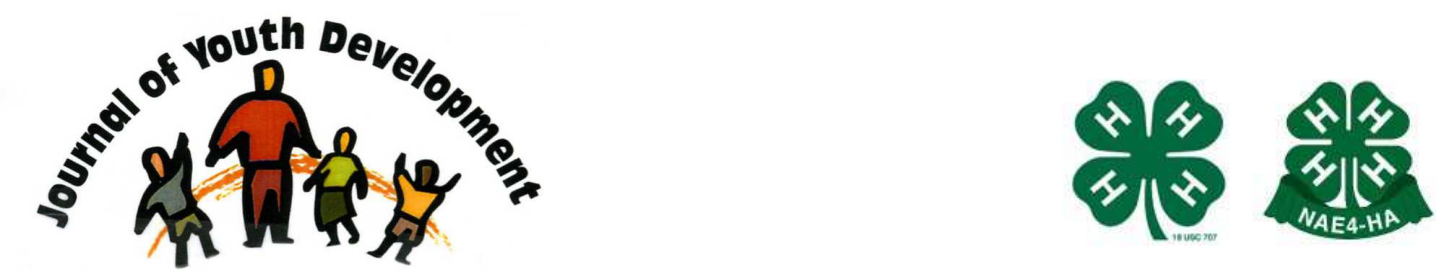

Bridging Research \& Practice

\title{
Do Higher Levels of 4-H Leadership Affect Emotional Intelligence?
}

\author{
Kalico Karr Leech \\ Texas Cooperative Extension \\ kalicokarrleech@srcaccess.net \\ Chris T. Boleman \\ Texas Cooperative Extension \\ College Station, TX \\ ct-boleman@tamu.edu \\ Cindy Akers \\ Texas Tech University \\ Lubbock, TX \\ Cindy.Akers@ttu.edu \\ Barry L. Boyd \\ Texas A \& M University \\ College Station TX \\ b-boyd@tamu.edu
}




\title{
JOURNAL OF YOUTH DEVELOPMENT \\ bridging research and practice

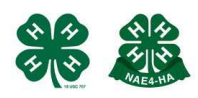

Volume 3, Number 3, Winter 2008

Article 080303RS003

\section{Do Higher Levels of 4-H Leadership Affect Emotional Intelligence?}

\author{
Kalico Karr Leech and Chris T. Boleman \\ Texas Cooperative Extension \\ Cindy Akers \\ Texas Tech University \\ Barry L. Boyd \\ Texas A \& M University
}

\begin{abstract}
The ex post facto, exploratory study sought to determine whether higher levels of 4-H leadership had an effect on level of emotional intelligence. Using the Bar-On Emotional Quotient Inventory $(E Q-i)$, the Texas 4-H Council $(n=32)$ answered questions related to five domains of emotional intelligence. The results for the five domains are as follows: "General Mood" = 104, "Intrapersonal" = 101, "Interpersonal" = 100, "Stress Management" = 100, "Adaptability" = 94 (Scale: effective emotional functioning $=100$ ). The overall EQ-I score was in the average range indicating that individuals in the group are functioning and healthy. Extension professionals should be aware of the lower scores related to "Adaptability" and "Stress Management." Some things Extension professionals should consider teaching youth include: ensuring youth goals are attainable, keeping youth focused on the issue at hand, establishing concrete protocols with youth, and teaching youth compassion for one another.
\end{abstract}

\section{Introduction}

Emotional Intelligence "is a type of social intelligence that involves the ability to monitor one's own and other's emotions to discriminate among them and to use the information to guide one's own thinking and action" (Mayer, \& Salovey, 1993). While Intelligence Quotient (IQ) has long been used as a predictor of a student's success, research now shows that Emotional 
Intelligence (EI) is a better predictor of "success" than the more traditional measures of cognitive intelligence. According to Pool (1997), IQ predicts only about 20 percent of career success while emotional intelligence predicts about 80 percent of a person's success in life.

When discussing emotional intelligence, it is important to remember that emotional intelligence is learned. It can be developed over time through understanding (emotional intelligence assessment tools) and thoughtful effort (training and development) to realize even greater benefits in personal performance and ultimately success in all aspects of life (Lajoie, 2002). According to Stein and Book (2001), a person's emotional intelligence quotient continues to rise with age.

Many youth programs, including 4-H, are focusing on the effectiveness of their leadership training. A general perception prevails that participation in a variety of activities or programs such as public speaking or holding office develops leadership life skills and self-understanding (Dormody, \& Seevers, 1994).

Boyd, Herring, and Briers (1992) stated that the level of 4-H participation was a significant predictor of leadership life skills development scores among 4-H youth in Texas. They observed higher leadership life skills development for 4-H members than non-members. Being a member of the Texas 4-H Council is the highest level of leadership attained at the state level in the Texas 4-H and Youth Development program; therefore, suggesting that members of the Texas 4-H Council should have higher life skills development.

\section{Purpose and Research Questions}

The purpose of the present study was to determine whether higher levels of 4-H leadership positively correlate with higher levels of emotional intelligence. The Texas 4-H Council was the group that was surveyed and tested to determine the following:

1. What is the emotional intelligence of Texas 4-H Council members?

2. What is the relationship between emotional intelligence and years in $4-\mathrm{H}$ ?

\section{Methods and Procedures}

This study was exploratory in nature; therefore, a descriptive survey design was used to execute the study (Ary, Jacobs, \& Razavieh, 1996). The study used an ex post facto approach and a correlational design. The purpose of the correlational research was to evaluate the relationships between multiple variables by using correlational statistics (Gall, Borg, \& Gall, 1996).

The population of this study was the 2005-2006 Texas 4-H Council members. This was a census study, encompassing all 32 members of the State 4-H Council. Schutt (2006) indicated that "in some circumstances it may be more feasible to skirt the issue of generalizability by conducting a census - studying the entire population of interest - rather than drawing a sample" (p. 138). He goes on to say social scientists don't usually attempt to collect data from all members of some large populations because it would be too expensive and time-consuming, and they could do almost as well with a sample. Due to the small size of the Texas 4-H Council, a census study was determined to be feasible and was used in this study, reaching all 32 of the members. 
The instrumentation for the study was the Bar-On Emotional Quotient Inventory (EQ-i) (Bar-On, 1996). The BarOn EQ-i, provided a total emotional quotient (EQ) score and five EQ composite scale scores comprising 15 subscale scores (Bar-On, 2002). The five scales are "Intrapersonal $\mathrm{EQ}$," "Interpersonal EQ," "Stress Management EQ," "Adaptability EQ," and "General Mood EQ" - each with its own set of subscales (Bar-On, 2002). The test was comprised of 133 items and employed a five-point response set, ranging from "not true of me" to "true of me." Approximately 30 to 40 minutes were needed to complete the exam; however, there were no imposed time limits. The scoring structure to this test was very similar to that of the intelligence quotient assessment (Bar-On, 2002). This test was developed by clinical psychologist Reuven Bar-On and was the first empirically constructed test of emotional intelligence that is commercially available (Bar-On, 2002).

The BarOn EQ-i instrument used to measure emotional intelligence was scored and interpreted by Multi-Health Systems, Inc. The $E Q-i$ has previously been shown to demonstrate sufficient test-retest reliability with .85 after one month and .75 after 4 months (Bar-On, 1996). The EQ-i variables in the five major domains of "Intrapersonal EQ," "Interpersonal EQ," "Stress Management EQ," "Adaptability EQ," and "General Mood EQ" were measured with 133 questions using a scale of $1=$ Very seldom or Not true of me, $2=$ Seldom true of me, $3=$ Sometimes true of me, $4=$ Often true of me, and $5=$ Very often true of me or True of me. The 133 questions dealt with

- self-regard,

- emotional self-awareness,

- assertiveness,

- independence,

- self-actualization,

- empathy,

- social responsibility,

- interpersonal relationships,

- stress tolerance,

- impulse control,

- reality testing,

- flexibility,

- problem solving,

- optimism, and

- happiness.

Six of the 32 Texas 4-H Council members were not able to attend the workshop; therefore, the instrument was mailed to them along with another parental consent form and a personalized letter of explanation. Before they were mailed, emails and telephone calls were made to each recipient to explain what they would be receiving in the mail (Dillman, 1978). All six of the instruments were returned. There was no difference in participants responding from the mailed survey versus participants responding via face to face administration.

SPSS 14.0 for Windows software was used for parts of the data analysis. The analysis of data was divided into two sections. The first section was the emotional intelligence section and the second section examined demographics of respondents. Inferential correlational and/or comparative techniques were used. These techniques included analysis of variance, independent and paired t-tests, and Pearson's product moment correlations. 


\section{Results and Discussion}

Profile of Respondents. Participants in the study were the 32 members of the 2005-2006 Texas 4-H Council. All members of the Texas 4-H Council were between the ages of 16 and 19 with the mean age being 17.31. Their years of 4-H participation ranged from 4-12 years with the mean years in $4-\mathrm{H}$ being 9.03 . The majority of the Texas 4-H Council members were male $(53.1 \%)$. The majority $(81.3 \%)$ of the Texas $4-\mathrm{H}$ Council members were white, two $(6.3 \%)$ were black, one (3.1\%) was American Indian or Alaskan Native, one (3.1\%) was Asian, and one (3.1\%) was Native Hawaiian or Pacific Islander. Following the format of questions asked on the Texas 4-H Enrollment Form, participants were asked in a separate question if they were of Hispanic ethnicity. Two youth (6.3\%) responded that they were of Hispanic ethnicity, and one of these marked that he was also white, the other did not choose a race.

Research Question 1. Emotional Quotient Inventory (EQ-I) scores may be classified as high, moderate, or low. In general, high scores identify areas of strength. Scores in the average range on these scales indicate typical healthy functioning and are scores that are obtained by the majority of those in the population who have taken the $E Q-i$. Lower scores reflect areas for development (Bar-On, 2006).

The Total EQ score obtained by the Texas 4-H Council members was about average (97). Usually a score in this range is obtained by a group that functions very well in some or most areas of emotional intelligence. A score of 100 represents effective emotional functioning. Scores greater than 100 represent enhanced emotional functioning, and scores of less than 100 indicate areas that may need improvement. This information is based on the average scores obtained by the group members, therefore it is important to keep in mind that the group results presented may not, and usually will not, apply to every single individual within the group (BarOn, 2006).

There are five composite scales used to determine EQ. The composite scales break Total EQ into the five domains of EQ for the Texas 4-H Council Members:

- Intrapersonal (101),

- Interpersonal (100),

- Stress Management (97),

- Adaptability (94), and

- General Mood (104). 
Figure 1 provides a graphical display of the group's composite scores.

Figure 1

Emotional Quotient Scores on the five Composite Scales by Texas 4-H Council Members N=32

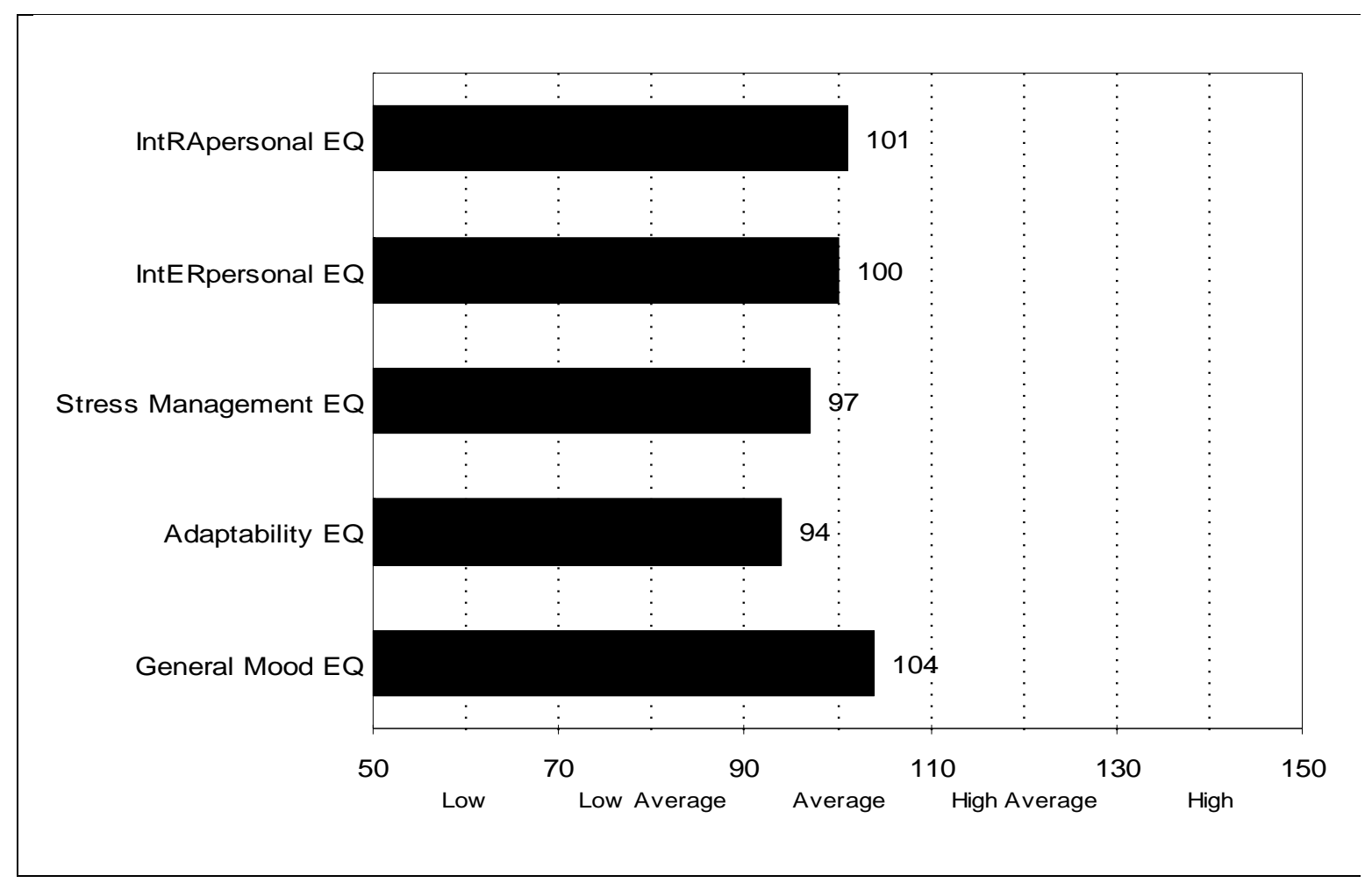

Within each of the five composite scales there are 15 subscales that provide scores and very focused information about specific skills within each of the domains of Intrapersonal, Interpersonal, Stress Management, Adaptability, and General Mood (Bar-On, 2006).

Intrapersonal $E Q$. The Intrapersonal composite score includes Emotional Self-Awareness, Assertiveness, Self Regard, Self-Actualization, and Independence. The group's Total Intrapersonal score (101) was about average overall, and scores on all of the subcomponents are also comparable to the norm (Bar-On, 2006).

- Self-Regard: The score on the self-regard scale (103) is slightly above average indicating a group with adequate self-respect and self-confidence. The Texas 4-H Council members probably have a reasonably good sense of who they are and have positive feelings about their life, lifestyle, and work most of the time (Bar-On, 2006).

- Emotional Self-Awareness: The score on this scale is about average (100). The emotional self understanding of the Texas 4-H Council members is moderate. Usually, emotional self-awareness assists interactions for this group, and attitudes are conveyed adequately. Nonetheless, improvement in this facet of emotional functioning may be of benefit (Bar-On, 2006). 
- Assertiveness: Collectively, the Council members' scores are above average (104) on the Assertiveness scale. This group should have an advanced ability to defend their beliefs, deal appropriately with others, and handle adversity. These Council members are probably forthright and confident and can openly share thoughts, beliefs, and feelings in a constructive manner. The group is likely perceived as non-threatening and provides freedom for exchanging ideas (Bar-On, 2006).

- Independence: The score on this scale is about average (97), indicating a balance between a desire to think and act independently and a willingness to make decisions in combination with other people (Bar-On, 2006).

- Self-Actualization: The score on this scale is reasonably high (103) and is indicative of a group of individuals who generally feel more content and self-fulfilled than the population norm. The score is indicative of a group whose members enjoy life most of the time and who usually stay involved in pursuits that are interesting and meaningful to them. Texas 4-H Council members are likely motivated and successful in what they do (Bar-On, 2006).

Interpersonal EQ. This component of the Total EQ-I scale taps interpersonal capacity and functioning. The subcomponents of the Total Interpersonal Scale include Empathy, Interpersonal Relationship, and Social Responsibility. The Total Interpersonal group score (100) was about average overall, but at least one of the subcomponents of interpersonal functioning was below average. Some social interactions are experienced as difficult, while others can be handled with the utmost ease and confidence. The subcomponent scores listed below will be helpful in understanding why some interpersonal situations are handled more easily than others (Bar-On, 2006).

- Empathy: The score on this scale (95) was slightly below average. While some of the time members of this group may have little difficulty understanding others and showing them consideration, there may be occasions when empathizing and giving proper regard to others is more difficult. As a result, some interactions will become strained due to thoughts and feelings being misunderstood (Bar-On, 2006).

- Social Responsibility: The results (99) indicated individuals who perceive themselves as being considerate and responsible most of the time. Sometimes self-aspirations are put ahead of the needs of others, but overall these individuals will be satisfactory contributors to the "community at large" (society, organization, team, etc.) (Bar-On, 2006).

- Interpersonal Relationship: The score (103) on this scale indicated a group with above average interpersonal skills overall. This is the scale that ties most directly to the ability to interact with others. Group members are able to form agreeable relationships and alliances. This ability supports effective communication and the mutually beneficial exchange of ideas, feelings, and information (Bar-On, 2006).

Stress Management EQ. The Stress Management component consists of the Stress Tolerance and Impulse Control Scales. The Total Stress Management EQ score (97) was below average, indicating that the scores obtained on both of the two subcomponents of Stress Management were low. This can indicate nervousness, anxiety, and difficulties handling stressful situations (Bar-On, 2006). 
- Stress Tolerance: The score (98) on the Stress Tolerance scale is a bit below average. The group probably has a reasonably normal ability to withstand adverse events and stressful situations. However, some circumstances may be difficult to handle for some individuals. Emotional outbursts and avoidance are probably common reactions to stress, but task-oriented coping efforts focused on problem resolution would be more adaptive (Bar-On, 2006).

- Impulse Control: The Impulse Control score (95) was below average indicating that group members have occasional or frequent difficulties resisting or delaying impulses, drives, and temptations to act. There may be problems avoiding overreacting, making impetuous decisions, and losing control. Some actions/decisions are likely made without adequate thought concerning all of the important implications (Bar-On, 2006).

Adaptability EQ. The Adaptability composite area is composed of the Problem Solving, Reality Testing, and Flexibility subscales and examines success in coping with environmental demands based on the ability to effectively size up and deal with problematic situations. The responses and score (94) of these individuals suggest some pretty important limitations in terms of adaptability. Sometimes the limitations can be due to an impractical approach to life that might be addressed by setting realistic goals. In other cases, the limitations are due to poor approaches to problem solving or the inability to adapt to changing demands (Bar-On, 2006).

- Reality Testing: The Reality Testing score (92) is quite low indicating a group with a pronounced tendency to be unrealistic and unfocussed. Group members may pursue unrealistic goals instead of sticking to practical and attainable goals. These Texas 4-H Council members may tend to lose focus on the task at hand and/or let their minds wander and become distracted (Bar-On, 2006).

- Flexibility: The group's Flexibility score (97) was slightly below average. Overall, the Council members may be slow to change opinions about things and to respond to shifting demands/needs. Some or most of the group members may be most comfortable performing clearly defined, regular tasks or assignments (Bar-On, 2006).

- Problem Solving: The group score (96) on the Problem Solving scale is a bit below average. Scores in this range are indicative of a group of individuals who have some success with their approach to problem resolution, but overall feel that improvement is possible in this area. Often improvement will come from approaching problems more methodically and systematically and by considering all of the possibilities before deciding what to do (Bar-On, 2006).

General Mood EQ. The subcomponents of this composite scale consist of Happiness and Optimism Scales. These components of the Total EQ-iscale measure contentment and overall outlook. Both components of General Mood were high for the Texas 4-H Council members (BarOn, 2006).

- Optimism: The score (101) on this scale is about average, indicating a level of optimism that is close to the population norm. There are probably times when members of this group feel a little pessimistic, but this is not necessarily unusual. Overall, optimism usually will be appropriate for the circumstances. Prospects for the future are assessed by keeping expectations balanced (Bar-On, 2006).

- Happiness: The score (106) on the Happiness scale is quite a bit above average and indicates Council members who feel satisfied with their lives and who get along well with 
others. This disposition can be infectious and can help energize and create an upbeat feeling in those around, fostering optimal functioning (Bar-On, 2006).

The overall $E Q$-i score was in the average range and indicates emotional functioning which is about typical for emotionally healthy individuals in the population. There were fairly large differences in the scores for the 15 content scales indicating areas of relative strengths and areas for improvement. The highest subscales were Happiness (106), Assertiveness (104), SelfActualization (103), Interpersonal Relationship (103), and Self-Regard (103). The lowest subscales were Reality Testing (92), Empathy (95), and Impulse Control (95). A graphical display of the Texas 4-H Council's averages for the $15 E Q-i$ subscales grouped by composite area is shown in Figure 2 (Bar-On, 2006). 
Figure 2

Emotional Quotient Scores on the 15 Subscales by Texas 4-H Council Members ( $\mathrm{N}=32)$

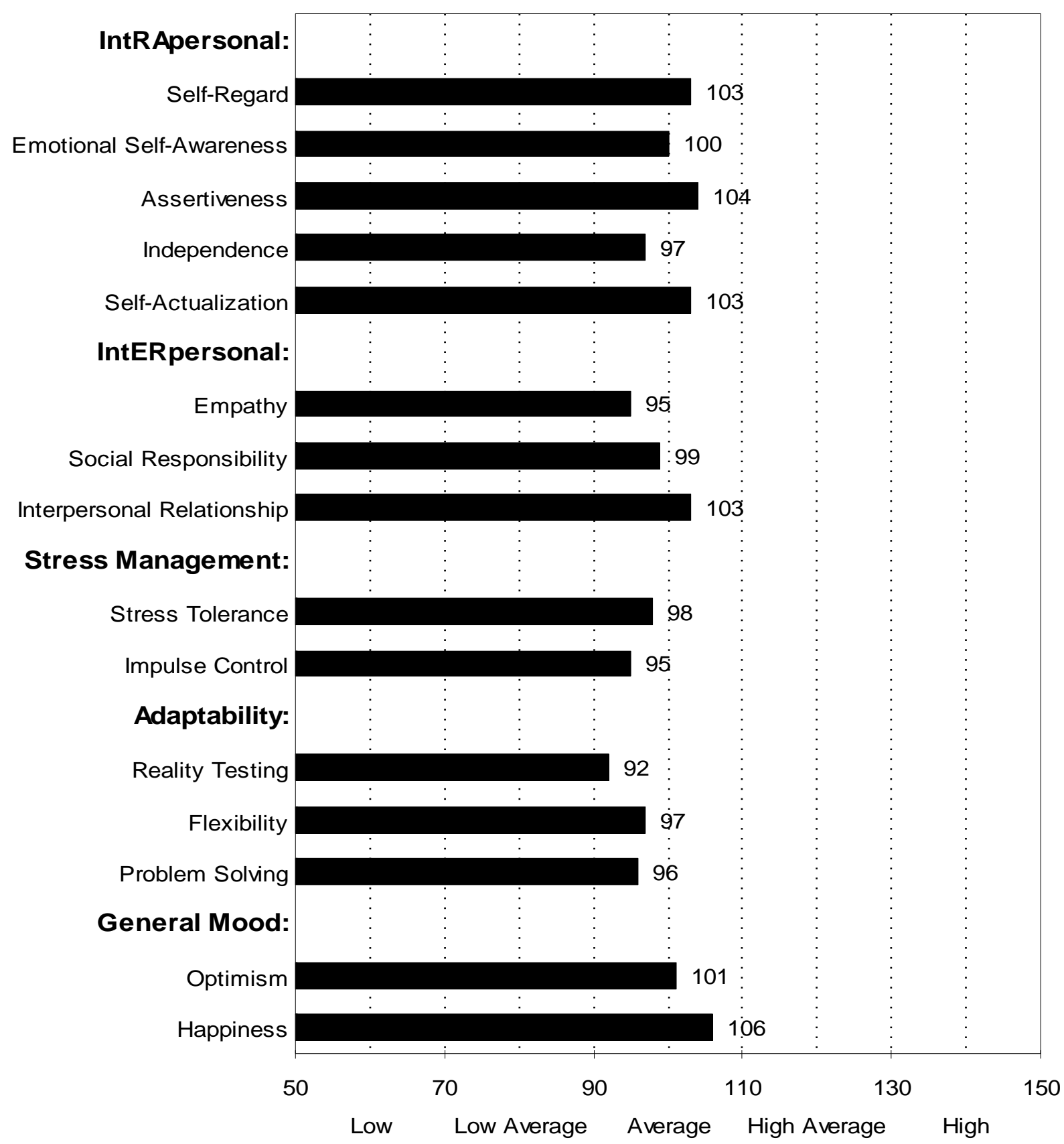

Research Question 2. A Pearson product moment correlation coefficient was conducted to determine the relationship between years in $4-\mathrm{H}$ and emotional intelligence (Table 1). There was nothing significant to report, but it is worth noting that Intrapersonal EQ $(r=.23)$ and Stress Management $(r=.20)$ both had low, positive relationships (Davis, 1971) with the years 
in the 4-H program, indicating that those who had been involved in the 4-H program longer had better scores in these areas.

Table 1

Pearson Product Moment Correlation Coefficients Between Years in 4-H and Emotional Intelligence in 2005-2006 Texas 4- $\mathrm{H}$ Council Members ( $\mathrm{N}=32)$

\begin{tabular}{|l|c|c|}
\hline Emotional Quotient Inventory & \multicolumn{2}{|c|}{ Years in 4-H } \\
\hline Total EQ & .04 & .22 \\
\hline Intrapersonal EQ & .23 & .22 \\
\hline Interpersonal EQ & .06 & .77 \\
\hline Stress Management EQ & .20 & .28 \\
\hline Adaptability EQ & .05 & .80 \\
\hline General Mood EQ & .10 & .58 \\
\hline
\end{tabular}

\section{Conclusions}

The Total EQ score obtained by the Texas 4-H Council members was about average (97). Usually a score in this range is obtained by a group that functions very well in some or most areas of emotional intelligence. A score of 100 represents effective emotional functioning. Scores greater than 100 represent enhanced emotional functioning, and scores of less than 100 indicate areas that may need improvement (Bar-On, 2006).

There are five composite scales used to determine EQ. The composite scales break Total EQ into the five domains of EQ scores for the 2005-2006 Texas 4-H Council Members: Intrapersonal EQ (101), Interpersonal EQ (100), Stress Management EQ (97), Adaptability EQ (94), and General Mood EQ (104). Within each of the five composite scales there are 15 subscales that provide scores and very focused information about specific skills within each of the domains.

There were fairly large differences in the scores for the 15 content scales indicating areas of relative strengths and areas for improvement. The highest subscales were Happiness (106), Assertiveness (104), Self-Actualization (103), Interpersonal Relationship (103), and Self-Regard (103). The lowest subscales were Reality Testing (92), Empathy (95), and Impulse Control (95).

\section{Recommendations}

The two Emotional Quotient domains on which the Texas 4-H Council members scored lowest were Adaptability EQ (94) and Stress Management EQ (97). The content subscales for Adaptability include "Reality Testing (92)," "Flexibility (97)," and "Problem Solving (96)." The content subscales within Stress Management EQ include "Stress Tolerance (98)" and "Impulse Control (95)." Of the 15, "Reality Testing" was the subscale that the Council members scored 
the lowest; "Impulse Control" and "Empathy" were the other two identified in the Bar-On EQ-i Group Report (2006) as the lowest scores. In order to address this, Texas 4-H teaching efforts and curriculum development should focus on "Reality Testing," "Impulse Control," "Empathy," "Problem Solving," "Stress Management," and "Stress Tolerance" - specifically for the youth, but they should also be addressed and included in professional development efforts of Extension faculty who work closely with the $4-\mathrm{H}$ members.

Specific recommendations (Bar-On, 2006) for addressing "Reality Testing" are to make sure goals are concrete and attainable and to ensure that observations/opinions are verified with alternate sources of information. The 4-H program is known for teaching goal setting (Karr, 2000), but in light of the findings, should perhaps help youth to increase their focus on practical actions; while ideals are desirable, they are sometimes not feasible. Also noted was the fact that inability to stay focused on the situation at hand is sometimes related to attention deficits or concentration lapses (Bar-On, 2006). This could be directly related to research that indicates attention-deficit/hyperactivity disorder (AD/HD), a neurological disorder characterized by developmentally inappropriate levels of inattention, impulsivity, and hyperactivity, affects 3 to 7 percent of school-age children (American Psychiatric Association, 2000; Mayo Clinic, 2002; Surgeon General of the United States, 1999; American Academy of Pediatrics, 2000, and National Resource Center on AD/HD, 2004). Increased novelty in activities/assignments to improve attention and removal of distractions from the immediate environment would assist in this area (Bar-On, 2006).

"Impulse Control" was another area Bar-On (2006) specifically addressed in relation to this group. Strategies for improvement in this area include establishing or enforcing protocols that require specific procedures/steps to help avoid rash actions. For important decisions, require the submission of formal listings of alternative actions, including an examination of the pros and cons of each action - allotting time and resources for verification of solutions. The importance of thinking before acting should be reinforced to 4-H members, as should listening/understanding before speaking. Other suggestions include setting priorities and avoiding diversions based on "whims" as well as using teams to balance/pair impulsive individuals with others who are more methodical (Bar-On, 2006).

When addressing "Empathy," another low scoring subscale for the Texas 4-H Council members, Bar-On (2006) suggests using job exchanges or job shadowing and make clear the duties/responsibilities of others with whom the youth are working, helping to promote an empathetic understanding between individuals. Also, opportunities for group members to interact and get to know each other on a personal level aids in facilitating empathy. Individually, 4-H members should learn to refine observational skills to notice facial expressions and body language as these cues are often just as important as what is being said. They should also learn to be "inquiring" in interactions, making sure that a message has been correctly interpreted and to understand the thoughts and feelings being conveyed. Finally, they should be able to "put oneself in the other person's shoes," ask questions of others, and find out about their activities, problems, and needs. The character education pillars of "caring" and "respect" should be used to help address empathy and compassion. Although research shows that youth involved in experiential education programs like 4-H report that they developed more empathy for others when compared to youth with no experiential education contact (Conrad, \& Hedin, 1981), more emphasis should be focused on empathy and compassion. 
Noting that the EQ scores of the Texas 4-H Council members were in relation to the general population, it is important to remember that the population for this study was youth and that a person's emotional intelligence quotient, as well as behavior and impulse control, will continue to increase with age (Bar-On, 2002; Stein, \& Book, 2001). Research on the ages and stages youth development show that while even in early childhood youth begin to experience empathy for others, they are still selfish (Tomek, \& Williams, 1999). Such social and emotional characteristics continue to develop through all stages of youth development and into adulthood. While social and emotional maturity continues to increase, in teenagers such as those on the Texas 4-H Council, the hormones and mood swings of puberty, the desire for peer acceptance and approval, and the need for independence play a role in emotional intelligence. The social/emotional maturation process is explained by Selman (1980) who developed social role taking stages that are viewed as a link between Piaget's logical reasoning stages and Kohlberg's moral reasoning stages. Selman places emphasis on the role of experience and learning, where advances in social perspective taking depend on the individual's experiences with others.

When discussing these subscales, descriptions that apply include: "Happiness" - this is a group who feels satisfied with their lives and who get along well with others. This disposition can be infectious and can help energize and create an upbeat feeling in those around fostering optimal functioning (Bar-On, 2006); "Assertiveness" - this group has an advanced ability to defend their beliefs, deal appropriately with others and handle adversity. This group is forthright and confident, and can openly share thoughts, beliefs, and feelings in a constructive manner. The group milieu is likely perceived as non-threatening and provides freedom for exchanging ideas (Bar-On, 2006); "Self-Actualization" - these individuals feel more content and self-fulfilled than the population norm, indicative of a group whose members enjoy life most of the time and who usually stay involved in pursuits that are interesting and meaningful to them. These are people who are motivated and successful at what they do (Bar-On, 2006); "Interpersonal Relationships" - this area ties most directly to the ability to interact with others. This group is able to form agreeable relationships and alliances, support effective communication, and the mutually beneficial exchange of ideas, feelings and information (Bar-On, 2006).

When sharing 4-H accomplishments with donors, emotional intelligence results and programming efforts should be shared as research suggests that people with high levels of emotional intelligence "experience more career success, build stronger personal relationships, lead more effectively, and enjoy better health than those with low [emotional intelligence] EQ" (Cooper, 1997, p.32). The fact that the 4-H program is producing these emotionally competent youth that will be assets and contributing, responsible adult members (Schlutt, 1987) to any university, workplace or community should be of interest to anyone helping to fund the 4-H program.

Currently there is limited research in the area of emotional intelligence and youth. Replicating this study within other youth programs such as FFA, FCCLA, or the Girl Scouts and Boy Scouts would be very beneficial to those working in youth development. 


\section{References}

American Academy of Pediatrics. (2000). Clinical practice guidelines: Diagnosis and evaluation of the child with attention-deficit/hyperactivity disorder. Pediatrics, 105, 1158-1170.

American Psychiatric Association. (2000). Diagnostic and statistical manual of mental disorders: DSM-IV (4 ${ }^{\text {th }}$ ed., text revision). Washington, D.C.: American Psychiatric Association.

Ary, D., Jacobs, L.C., \& Razavieh, A. (1996). Introduction to research in education. (5 $5^{\text {th }}$ ed.). Fort Worth, TX: Harcourt Brace College Publishers.

Bar-On, R. (2002). BarOn emotional quotient inventory: Technical manual. New York: MultiHealth Systems, Inc.

Bar-On, R. (1996). The emotional quotient inventory: A test of emotional intelligence. Toronto, Canada: Multi-Health Systems, Inc.

Bar-On, R. (2006). The emotional quotient inventory group report: A test of emotional intelligence. Toronto, Canada: Multi-Health Systems, Inc.

Boyd, B.L., Herring, D.R., \& Briers, G.E. (1992). Analysis of 4-H participation and leadership life skill development in Texas 4-H club members. Proceedings of The National Agricultural ducation Research Meeting, 1994. 81-89.

Conrad, D., \& Hedin, D. (1981). National assessment of experiential education: A final report. University of Minnesota, St. Paul, Center of Youth Development and Research. (ERIC Document Reproduction Service, ED 223 765).

Cooper, R. (1997). Applying emotional intelligence in the workplace: Part 2 of a 2-part article. Training \& Development, 51(12), 31-38.

Dillman, D.A. (1978). Mail and telephone surveys: The total design method. New York: John Wiley \& Sons.

Dormondy, T.J., \& Seevers, B. (1994). Predicting youth life leadership skills development among senior 4-H members: A tri-state study. The Journal of Agricultural Education, 35(3), 64.

Gall, M.D., Borg, W.R., \& Gall, J.P. (1996). Educational research: An introduction ( $6^{\text {th }}$ ed.). White Plains, NY: Longman Publishers.

Karr, K. (2000). The self-perceived impact of participation in the Texas 4-H Council by former Council members. Unpublished master's thesis. Texas Tech University, Lubbock, TX.

Lajoie, D. (2002, Autumn). The emotional intelligence explosion. Moving Business Forward. Retrieved September 24, 2004 from: http://www.guelphchamber.com

Mayer J.D., \& Salovey, P. (1993). The intelligence of emotional intelligence. Intelligence, 17, 422-433. 
Mayo Clinic. (2002). How common is attention-deficit/hyperactivity disorder? Archives of Pediatrics and Adolescent Medicine, 156 (3), 209-210.

National Resource Center on AD/HD. (2004). The disorder named AD/HD. What We Know, 1.

Pool, C.R. (1997, May). Up with emotional health. Educational Leadership, 54, 12-14.

Schlutt, E.F., Jr. (1987). Impact of youth program membership on youth program life skills development, youth program experiences, adult community participation, and personal characteristics related to 4-H volunteerism. Unpublished doctoral dissertation, Texas A\&M University, College Station.

Schutt, R.K. (2006). Investigating the social world: The process and practice of research (5 $5^{\text {th }}$ ed.). Pine Forge Press: Thousand Oaks, CA.

Selman, R.L. (1980). The growth of interpersonal understanding: Developmental and clinical analyses. New York: Academic Press.

Stein, S.J., \& Book, H.E. (2001). The EQ edge. Toronto, Canada: Stoddart Publishing Co. Limited.

Surgeon General of the United States. (1999). Mental health: A report of the Surgeon General. Rockville, MD: U.S. Department of Health and Human Services.

Tomek, J., \& Williams, M.J. (1999). Ages and stages of 4-H youth development. MU Extension, University of Missouri-Columbia.

(C) Copyright of Journal of Youth Development $~$ Bridging Research and Practice. Content may not be copied or emailed to multiple sites or posted to a listserv without copyright holder's express written permission. Contact Editor at: patricia.dawson@oregonstate.edu for details. However, users may print, download or email articles for individual use.

ISSN 2325-4009 (Print); ISSN 2325-4017 (Online) 